\title{
Correction to: Neuro-radiological characteristics of adult diffuse grade II and III insular gliomas classified according to WHO 2016
}

\author{
Paloma Compes $^{1,2} \cdot$ Emeline Tabouret $^{1,3}$ (1) $\cdot$ Amandine Etcheverry $^{4} \cdot$ Carole Colin $^{1} \cdot$ Romain Appay $^{1,5}$. \\ Nicolas Cordier ${ }^{6} \cdot$ Jean Mosser ${ }^{4} \cdot$ Olivier Chinot $^{1,3} \cdot$ Hervé Delingette $^{6} \cdot$ Nadine Girard $^{7} \cdot$ Henry Dufour $^{2}$. \\ Philippe Metellus ${ }^{1,8} \cdot$ Dominique Figarella-Branger ${ }^{1,5}$
}

Published online: 11 March 2019

(c) Springer Science+Business Media, LLC, part of Springer Nature 2019

\section{Correction to: Journal of Neuro-Oncology} https://doi.org/10.1007/s11060-019-03122-1

In the initial, online publication, the authors' given names were captured as family names and vice versa. The names are correctly shown here. The original article has been corrected.

Publisher's Note Springer Nature remains neutral with regard to jurisdictional claims in published maps and institutional affiliations.

The original article can be found online at https://doi.org/10.1007/ s11060-019-03122-1.

Dominique Figarella-Branger

dominique.figarella-branger@univ-amu.fr

1 Aix-Marseille Univ, CNRS UMR 7051, INP, Inst Neurophysiopathol, Marseille, France

2 AP-HM, Hôpital de la Timone, Service de Neurochirurgie, Marseille, France

3 AP-HM, Hôpital de la Timone, Service de Neurooncologie, Marseille, France

4 Integrated Functional Genomics and Biomarkers Team, UMR6290, CNRS, Université de Rennes 1, Rennes, France

5 AP-HM, Hôpital de la Timone, Service d'Anatomopathologie, Marseille, France

6 Université Côte d'Azur and Inria Sophia-Antipolis Méditerranée Asclepios Team, Inria Sophia Antipolis, Sophia Antipolis, France

7 Aix Marseille University UMR CNRS 7339, APHM Timone Hospital, Marseille, France

8 Department of Neurosurgery, Clairval Private Hospital, Ramsay Generale de Sante, 13009 Marseille, France 